\title{
HOMO RISIBILIS
}

\author{
Lydia Amir*
}

RESUMEN: En este artículo se propone que el humor constituye una forma de comunicación intrapersonal particularmente apta para la (auto) educación filosófica que se encuentra en el corazón de la práctica de la filosofía. Se explican los resultados epistemológicos y éticos de un uso sistemático de la risa autorreferencial. Se defienden los beneficios de una cosmovisión basada en el reconocimiento del ridículo humano, Homo risibilis, comparándolo con otros enfoques de la condición humana.

$$
\text { শ্ৰ }
$$

\section{Homo RisiBILIS}

ABSTRACT: This article presents humor as enacting an intra-personal communication particularly apt for the philosophic (self) education that lies at the heart of the practice of philosophy. It explains the epistemological and ethical outcomes of a systematic use of self-referential laughter. It argues for the benefits of a worldview predicated on acknowledging human ridicule, Homo risibilis, comparing it with other approaches to the human predicament.

PALABRAS CLAVE: autoeducación, comunicación, humor, ridiculización, tragedia.

KEY WORDS: communication, humor, ridicule, self-education, tragedy.

RECEPCIÓN: 26 de febrero de 2020.

Aprobación: 19 de marzo de 2020.

DoI: $10.5347 / 01856383.0133 .000299229$

* Colegio Académico Beit Berl, Israel. Profesora invitada, Universidad de Tufts. 
Se prohíbe su reproducción total o parcial por cualquier medio, incluido electrónico, sin permiso previo y por escrito de los editores. 


\section{HOMO RISIBILIS*}

Quid rides? Mutato nomine de te fabula narratur (¿De qué te ríes? Si cambias el nombre, la historia se refiere a $\mathrm{ti})$ Horacio, Sátiras I, 1, 69

E1 humor autorreferencial constituye una forma de comunicación intrapersonal particularmente apta para la (auto) educación filosófica que se encuentra en el corazón de la práctica de la filosofía. Este tipo de humor crea dentro de uno mismo una división entre dos partes que mantienen "relaciones de broma" entre sí. Este último término fue acuñado por el antropólogo Radcliffe-Brown para denotar las relaciones existentes entre los miembros de la misma familia, cuyas posiciones dan lugar a conflictos potenciales. El propósito de establecer "relaciones de broma" es desahogar la agresión implicada en estas relaciones. ${ }^{1}$

Del mismo modo, postulo que un filósofo que toma la filosofía seriamente mantiene relaciones conflictivas consigo mismo. Está comprometido en un proceso de autoeducación de toda la vida cuyo propósito es moldear un carácter estable y apto para una vida filosófica; sin embargo, este carácter está mayormente en desacuerdo con los valores sociales

* Tradución de Alfredo Gerardo Martínez Ojeda. Este artículo se traduce del inglés y se publica con el permiso de la American Philosophical Practitioners Association (APPA). Publicado originalmente en Philosophical Practice: Journal of the APPA, 9/3 (2014), pp. 1487-1497.

${ }^{1}$ Alfred Reginald Radcliffe-Brown, Structure and function in primitive society: Essays and addresses, 1952, Nueva York, The Free Press, pp. 90-116. 
y, por lo tanto, con la parte de su ser que ha sido socializada. Así, el filósofo está dividido necesariamente entre un yo mejor (más filosófico, racional, objetivo, ético, coherente, maduro) y una parte "impugnada" de sí mismo, que se resiste al cambio (un yo social, emocional, autofocalizado, errático, inmaduro).

Esta división entre un "yo mejor" y un "yo peor" puede recordar la división tradicional entre ideal y realidad, con una diferencia importante. La división tradicional es neutra con respecto a la minimización de la brecha entre lo ideal y lo real. En cambio, la división dentro del yo que el humor representa es una relación dialógica, una agresión compasiva que minimiza inmediatamente la tensión entre las partes del yo y puede conducir a un cambio interior. La agresión compasiva es necesaria tanto para el mínimo de autoaceptación que es un requisito para el autocambio, como para el cambio mismo. A su vez, el cambio interior es necesario para la plena autoaceptación, que está en la raíz de varios beneficios éticos y epistemológicos, como veremos en breve.

La contradicción entre "compasión” y "agresividad”, o entre unir y distanciar, o de nuevo, cercano y lejano, es solo una de las contradicciones que conforman el concepto de humor. La explicación es que el humor

74 conserva unidas ideas o emociones desarticuladas y mantiene relaciones ambiguas con la verdad. Las contradicciones del humor reflejan los puntos de vista contradictorios que forman la ambivalencia que todos experimentamos como parte de nuestra constitución psicológica, y la posición ambigua que la verdad mantiene entre las ilusiones queridas y las perspectivas extremas y desproporcionadas.

Necesitamos una herramienta conceptual que mantenga las contradicciones que constituyen nuestras experiencias de nosotros mismos, de los demás y del mundo en general. Paradójicamente, hasta que no hagamos uso de esta herramienta no podremos reconocer plenamente estas contradicciones. Asimismo, necesitamos una herramienta para manejar la razón y las emociones juntas, y hasta que no la tengamos en nuestro poder no experimentaremos plenamente el punto de vista personal que son las emociones o el punto de vista más objetivo que la 
razón representa, y ciertamente no los dos puntos de vista juntos. Por último, necesitamos una herramienta para manejar nuestro sufrimiento, el sentido trágico de la (nuestra) vida, sin perder el entusiasmo por la vida que permite nuestra supervivencia. La risa autorreferencial, o humor, es esa herramienta.

Desafortunadamente, experimentamos la contradicción como conflictiva y el conflicto como violento, desesperanzado e ineficaz. Como desquiciante experiencia de nuestra impotencia, preferimos evitar el conflicto a toda costa. A diferencia de los conflictos externos, que a veces pueden ser resueltos por el puro poder, los conflictos internos no pueden ser "resueltos" sin pérdidas. El acoso interno o la opresión de una parte del yo mediante la fuerza de voluntad pueden ser productivos en algún caso aislado, pero resultan contraproducente para promover el cambio.

Si fuéramos plenamente racionales, si fuéramos capaces de un cambio radical e instantáneo y si viviéramos sin conflictos con los demás, no necesitaríamos el humor. Debido a que estamos hechos de contradicciones conflictivas, el humor es una herramienta de supervivencia para la especie. Esta idea se deriva de la errónea pero prolífica caracterización del ser humano como el único animal que ríe, Homo ridens. Originado por extrapolación de la frase de Aristóteles, "el hombre es el único animal que ríe" (una observación empírica sobre la reacción fisiológica humana al cosquilleo), la tradición del Homo ridens alcanzó su apogeo en la Edad Media y en el Renacimiento. En la Edad Media, porque los estudiosos identificaban la racionalidad con la capacidad de reír, y en el Renacimiento, porque la risa se consideraba apta para un mundo que no es un valle de lágrimas y para un ser hecho de contradicciones. Julio Pólux, Galeno, Porfirio, Marciano Capella, Boecio, Alcuino, Notker Labeo, Joubert, Montaigne, Rabelais, Leopardi, Baudelaire, Voltaire, Schopenhauer y Sartre, entre otros, pertenecen a esta tradición. ${ }^{2}$

La risa autorreferencial, tan útil como rara, es la forma más potente de humor. Ya lo había notado Demócrito, el risueño filósofo del siglo v a.C., quien señala este punto ciego como su principal razón para reírse de la humanidad: "Ustedes no se ríen de su propia estupidez,

${ }^{2}$ Cfr. Amir, "Philosophy's attitude toward the comic-A reevaluation", The European Journal of Humor Research, 1/1 (2013), pp. 6-21. 
sino que cada uno se ríe de la de los demás". ${ }^{3}$ Desde la advertencia de Demócrito, la risa autorreferencial es adoptada por sus seguidores. "Nadie es el hazmerreír de sí mismo", dice Séneca. ${ }^{4}$ También defendida por Montaigne ${ }^{5}$ y por More, según Erasmo, ${ }^{6}$ la risa autorreferencial fue popularizada por Nietzsche ${ }^{7}$ y Santayana. ${ }^{8}$ También es característica del emblemático profesor de filosofía Sócrates. Dado que por lo regular leemos los diálogos de Platón y entendemos a Sócrates con el prejuicio de la definición moderna de la ironía, esta característica puede ser pasada por alto. Permítanme, por tanto, desarrollar el humor autorreferencial de Sócrates.

Como en la Antigüedad no se asociaba la ironía con la broma, ${ }^{9}$ el humor de Sócrates difiere de su ironía. Si en los Diálogos Sócrates es considerado irónico en el sentido griego de la ironía (por decir lo contrario de lo que es cierto), no por ello es menos gracioso (bromea incluso sobre sí mismo). En La risa griega, el gran erudito en la Antigüedad clásica Stephen Halliwell sostiene que el Sócrates platónico se caracteriza por la "burla de sí mismo". El tema del ridículo interiorizado se menciona fugazmente cerca del final de Fedón, pero también se atisba en varios pasajes en los que Sócrates ofrece una crítica de argumentos que había defendido, como el final del Carmides y en el Protágoras, 361a. La risa autorreferencial también se encuentra en el famoso discurso de las leyes en el Critón y en la risa que Diotima, el alter ego de Sócrates, le dirige a Sócrates en el Simposio. ${ }^{10}$

Así, aunque al Sócrates de Platón no le falta la capacidad de ridiculizarse él mismo, en los escritos de otro discípulo reputado, Jenofonte,

${ }^{3}$ Hippocrates, Pseudepigraphic writings, 1990, Leiden, Carta 17, línea 5.

${ }^{4}$ Séneca, On firmness, 16.3-17.4, en Moral and political essays, 1995, Cambridge, Cambridge University Press, trad. de John M. Cooper y J. R. Procope.

${ }^{5}$ Montaigne, The complete essays, 1958, Stanford, Stanford University Press, trad. de Donald Frame, p. 503.

${ }^{6}$ Erasmo, Opus epistolarum de Erasmi Roterodami, Epístola 999, 4.

${ }^{7}$ Friedrich Nietzsche, Thus spoke Zarathustra, 1954, Nueva York, Vintage, IV, 12, 18 y 20.

${ }^{8}$ George Santayana, Dialogues in limbo, 1948, Nueva York, Scribner's, pp. 44 y 45.

${ }^{9}$ Dilwyn Knox, Ironia: Medieval and Renaissance ideas on irony, 1989, Leiden, E.J. Brill, p. 102.

${ }^{10}$ Stephen Halliwell, Greek laughter: A study of cultural psychology from Homer to early Christianity, 2008, Nueva York, Cambridge University Press, pp. 291-292. 
encontramos las evidencias más claras del humor socrático. Jenofonte describe a su maestro como aficionado a la risa, el baile y los juegos de palabras: "Cuando bromeaba —informa Jenofonte - no era menos provechoso para los que pasaban tiempo con él que cuando era serio". ${ }^{11}$ Del mismo modo, Jenofonte comienza su Simposio con la siguiente afirmación: "En mi opinión, vale la pena relatar no solo los actos serios de los grandes y buenos hombres, sino también lo que hacen en sus momentos más ligeros". La asistencia de Sócrates a la representación de Las nubes para que el público ateniense pudiera juzgar qué tan bien había captado Aristófanes su imagen - según cuenta Diógenes Laercio-,${ }^{12}$ atestigua ciertamente su sentido del humor. ${ }^{13}$

Sin embargo, la contribución de Platón a la risa sobrepasa su representación de Sócrates. El ojo perceptivo de Platón hizo de la autoignorancia de los individuos impotentes (la mayoría de nosotros) lo verdaderamente cómico. ${ }^{14}$ Revela así sus diálogos como comedias filosóficas y a sí mismo como el escritor de la tragedia y de la comedia que Sócrates elogia al final del Simposio. ${ }^{15}$ De hecho, todas las obras de Platón reflejan el drama cómico actual y utilizan técnicas cómicas, ${ }^{16} \mathrm{y}$, mientras que algunas de las obras de Platón son tragicomedias (Simposio, República), otras, como el Cratilo y el Eutidemo, están infundidas con un espíritu de comedia tan visible que se convierten en burlesque. ${ }^{17}$ Sin embargo, tendemos a reírnos de aquellos que son blanco de Platón creyendo que no llevamos nuestra propia ración de autoignorancia. Ahí radica la distintiva ironía platónica sugerida por el epígrafe de Horacio que abre este artículo: “¿De qué te ríes? Si cambias el nombre, la historia se refiere a ti”.

${ }^{11}$ Jenofonte, Memorabilia IV, 1, 1.

${ }^{12}$ Cfr. Diógenes Laercio, Lives of eminent philosophers, 1925, Cambridge, Harvard University Press, trad. de R.D. Hicks.

${ }^{13} \mathrm{Cfr}$. Amir, "The value of dissatisfaction-Maintaining the tension that unites desires and reason", Axiology and Ethics, número especial por la 23ra. Reunión Mundial de Filosofía (2014), pp. 46-57.

${ }^{14}$ Platón, Filebo $48 \mathrm{a}-50 \mathrm{~b}$.

${ }^{15}$ Simposio 223d.

${ }^{16}$ Roger Brock, "Plato and Comedy", en E.M. Craik (comp.), "Owls to Athens": Essays on classical subjects presented to Sir Kenneth Dover, 1990, Oxford, Clarendon Press, pp. 39-49.

${ }^{17}$ Charles L. Griswold, "Irony and aesthetic language in Plato's Dialogues", en Doug Bolling (comp.), Philosophy and literature, 1987, Nueva York, Haven, pp. 87-88. 
Cabe destacar que Daniel Dennett ve el humor autodirigido como el paradigma de todo el humor, ${ }^{18}$ en oposición con Roger Scruton, por ejemplo, quien afirma que "el humor no es normalmente autodirigido". ${ }^{19}$ Sin embargo, la relativa falta de risa autorreferencial puede explicar cómo puede ser constitutiva de la conciencia filosófica: saber que uno mismo está haciendo (o siendo) ridículo te afirma como filósofo o al menos apunta al componente filosófico de tu Dasein. Ser ridículo ya implica una inserción filosófica, porque implica el acto de reírse de uno mismo. En l'Essence du rire Baudelaire define esta capacidad de reírse de sí mismo al caer (irse de espaldas, de vuelta a la infancia, de vuelta a la vejez) como el momento constitutivo de la conciencia filosófica. Lo que Paul de Man interpreta como ironía - el filósofo se divide en dos, acelerando el tiempo mientras se colapsa sobre sí mismose establece por la caída designando una división entre el amigo mudo, por un lado, y el que ridiculiza al ego vacilante, por el otro. Cuando el filósofo cae, provocando el acto de apertura en la $u r$-scene $e^{20}$ (escena) de la conciencia filosófica, esto produce el doble efecto de la conciencia irónica. El sujeto se ríe de sí mismo al caer; en efecto, la caída anuncia el momento en que el sujeto se convierte en filósofo por medio, precisamente, de reírse de sí mismo, haciéndose ridículo, sich lächerlich machen. Afectada por la risa del otro, la conciencia filosófica se hace realidad pasando por el momento constituyente de ridiculizarse. Reírse de uno mismo distingue al filósofo del no filósofo en la medida en que se toma una posición fuera del yo desde la que este puede observarse en sí mismo. El momento acelera violentamente la historia del yo y su caída: reírse de uno mismo es reírse de uno mismo muriendo desde una posición improbable más allá o al otro lado de una vida que se ha disociado por el repentino deslizamiento en la conciencia. ${ }^{21}$

\footnotetext{
${ }^{18}$ Matthew M. Hurley, Daniel C. Dennett, Reginald B. Adams, Jr., Inside jokes: Using humor to reverse-engineer the mind, 2011, Cambridge, MIT Press, pp. 131-133.

${ }^{19}$ Roger Scruton, "Laughter", en John Morreall (comp.), The philosophy of laughter and humor, 1987, Albany, SUNY Press, p. 169.

${ }^{20}$ Del alemán Urszene: término asociado al psicoanálisis freudiano que indica una escena original en el sentido de aquella que deja una impronta fundacional (N. del T.).

${ }^{21}$ Avital Ronell, Stupidity, 2003, Urbana y Chicago, University of Illinois Press, pp. 298-299.
} 
Los no filósofos se ríen de los demás, los filósofos se ríen de sí mismos. Asombrarnos ante nuestra necesaria pero imposible ridiculización, postulo, es lo que nos impulsa a filosofar.

La risa autorreferencial representa una comunicación intrapersonal que contrapone una parte con la otra, como el patiño y el bromista que

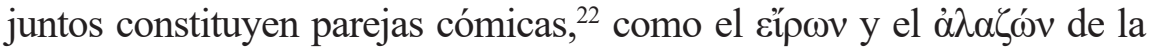
comedia griega que Aristóteles describe en su Ética Nicomaquea. ¿Quién se ríe de quién, dentro del yo? Para Schopenhauer, lo irracional es lo que finalmente tiene la oportunidad de razonar. Para otros pensadores, es la razón la que se ríe del resto de nosotros mismos. En cualquier caso, la risa es imposible a menos que la persona que ríe se sienta superior o por encima de la situación de la que se está riendo. Así, para poder reírse de alguien, su opuesto necesita un punto de vista, un pensamiento con el que alinearse, una visión relativamente segura desde cuya perspectiva la otra parte parece errónea, inadecuada o inmadura.

Las teorías filosóficas proporcionan fácilmente los ideales que pueden ser utilizados como puntos de vista desde los cuales uno mismo es examinado con humor. Sin embargo, para que la risa autorreferencial sea eficaz como agente de cambio, uno tiene que alinearse sucesivamente, por así decirlo, con varias partes del yo en conflicto. De hecho, esto ejemplifica la aparentemente paradójica capacidad del humor para unir y distanciar al mismo tiempo: ¿no se ha elogiado al humor como la distancia más corta entre dos seres humanos y se ha demostrado que el ridículo es un arma mortal? A veces se dice que la resolución de este acertijo radica en la forma de humor que se usa. En efecto, la fórmula del humor exitoso cambia según la relación entre agresión y compasión: el mínimo de compasión disminuye mientras que el mínimo de agresión aumenta. Ahora bien, sostengo que cualquier tipo de humor une y distancia al mismo tiempo y que el aspecto social del humor se mantiene también en el humor intrapersonal. La unidad que el humor representa se logra principalmente a través del distanciamiento común:

${ }^{22}$ Cfr. Anna Beltrametti, "Le couple comique: Des origins mytiques aux derives philosophiques", en Marie-Laurence Desclos (comp.), Le Rire des grecs: Anthropologie du rire en Grèce ancienne, 2000, Grenoble, Jérome Millon, pp. 215-226. 
no solo el "yo" se alinea con una parte de mí mismo contra otra, sino que al abrazar un punto de vista contra otro "yo" se une a él debido a nuestro distanciamiento conjunto de otra parte.

Somos tan rápidos como la parte más lenta en nosotros, y tan alegres como nuestro sentimiento más melancólico. Ninguna acción puede tener éxito si nuestras fuerzas están divididas. No se puede construir ninguna alegría o felicidad duradera sobre la lucha y ninguna serenidad sobre la discordia. Mediante relaciones internas humorísticas, se puede asegurar la cooperación entre varias facciones del yo después de que se hayan emprendido procesos de introducción, reconocimiento mutuo y cercanía con vistas a la integración de la personalidad.

\section{II}

Aunque varias contradicciones y conflictos pueden ser minimizados de esa manera, los que quedan son constitutivos de la condición humana. Definida de diversos modos, la condición humana ha sido interpretada frecuentemente como paradójica y el ser humano como contradictorio. Mientras que el humor es eficaz para reducir la tensión de estas contradicciones inherentes cuyas instancias experimentamos a diario, la base común de la mayoría de las religiones y filosofías, tanto orientales como occidentales, ha sido resolver la contradicción constitutiva. Puede definirse como la discrepancia entre nuestros deseos en los niveles instintivo, emocional e intelectual, y nuestra conciencia de la imposibilidad de cumplirlos, tanto por razones prácticas como de principios. Esta descripción de la situación humana se ajusta a la visión de Camus, Sartre, Kant y Freud de las relaciones que mantenemos con el mundo, con los demás y con nosotros mismos, aunque no las describan en esos términos.

Las soluciones a la condición humana tienen un precio. Si encontráramos una manera de soportar, si no de disfrutar, esta contradicción, sería mejor no deshacernos de nuestra humanidad renunciando a uno de los polos que la definen: los deseos, por un lado, y la (im)posibilidad 
racional de cumplirlos, por el otro. Los deseos son espirituales, intelectuales, emocionales, instintivos y abarcan desde el anhelo hasta el sentido y la comprensión, desde el amor y la felicidad hasta las necesidades de sexo y comida. Y, nuestros poderes racionales o cognitivos nos iluminan sobre las razones prácticas o de principios que hacen imposible que satisfagamos nuestros deseos. La reducción de la tensión que permite el humor nos ayuda a optar por dejar deliberadamente sin resolver el conflicto humano básico.

Es posible que queramos dejar el conflicto sin resolver cuando el precio de resolverlo requiera renunciar a nuestros poderes racionales o a los deseos con los que nos identificamos en no menor medida que con nuestra razón. La mayoría de las soluciones religiosas y filosóficas al problema humano básico requiere renunciar a uno o más aspectos de nuestra humanidad tal como la conocemos. Las teorías de la redención o de la paz mental, ya sea oriental u occidental, religiosa o no religiosa, se pueden dividir en tipos generales. El primer tipo niega el deseo. Incluye, entre otros, la visión budista e hindú de la liberación, la teoría de la redención de Schopenhauer (que está influida por la primera), las escuelas helénicas de epicureísmo y pirronismo, e incluso la visión sobre la emancipación de un filósofo tan razonable como Bertrand Russell. El segundo tipo de teorías deja en evidencia las limitaciones de la razón. Incluye todas las respuestas a las preguntas metafísicas, las teorías religiosas y las diversas filosofías que fomentan la satisfacción de nuestros deseos a expensas de otros seres humanos, cuyo derecho similar nos es revelado por la razón, como el nietzscheanismo. El tercer tipo de teorías denigra tanto el deseo como la razón: es ejemplificado por el taoísmo y algunas formas de misticismo occidental, pero también por aquellas filosofías que sobrepasan el poder de la razón mientras denigran los deseos, como el estoicismo y la visión de Kant de la buena vida como una vida vivida de acuerdo con el imperativo categórico. ${ }^{23}$

He explicado en otra parte cómo se puede soportar la contradicción humana básica a través de un humor que reduce su tensión convirtiendo

${ }^{23}$ Cfr. Amir, Humor and the good life in modern philosophy: Shaftesbury, Hamann, Kierkegaard, 2014, Albany, SUNY Press. 
las oposiciones trágicas en incongruencias cómicas. ${ }^{24}$ Permítanme argumentar ahora que esto no es suficiente. Debemos aprender la lección de una vez por todas descubriendo nuestra locura constitutiva en lugar de reírnos de la locura de los demás, como diría Michel de Montaigne, ${ }^{25}$ y riéndonos de nosotros mismos mientras nos reímos de un marido traicionado que una y otra vez confía en su esposa infiel, como sugiere Giacomo Leopardi. $^{26}$

Nos negamos a aprender la lección, porque el entusiasmo de la vida que condiciona los factores iniciales de nuestro éxito en la supervivencia parece depender de nuestras ilusiones. El amor a la vida, a los otros, a nosotros mismos, debería ser (para ser verdaderamente amor) completamente ciego, o eso es lo que pensamos. La alegría debería ser irracional porque creemos que está condicionada por nuestra miopía. No podemos abrazar la muerte en nuestra visión, ni la incertidumbre del mañana ni las penas del ayer en una sola mirada. Como no podemos desarrollar un gusto por la realidad, necesariamente la deformamos.

Oscar Mandel sostiene en Tragic reality que "el fracaso está implícito en el esfuerzo". No solo la muerte, con su inevitable victoria sobre el esfuerzo, hace trágico el nacimiento, sino que la necesidad de vivir entre los de su especie es trágica debido a la "desarticulación entre los seres humanos, que hace que el niño se vea obligado a sufrir entre los de su propia especie". ${ }^{27}$ Mandel señala la complejidad de la locura en la sabiduría, la fatalidad en el éxito, el defecto en toda reforma social: atracción y repulsión, amor y odio, ilusión y desilusión, reforma y reacción, esperanza utópica y desesperación final; estos son los materiales bien conocidos de las tragedias modernas, que deben terminar, si el artista no ve la justicia en "los dos lados de todo", con una nota de inutilidad y desesperanza. ${ }^{28}$

${ }^{24}$ Amir, "Humor in philosophy-Theory and practice", Philosophical Practice, 7 (2012), pp. 1015-1029.

${ }^{25}$ Loc. cit.

${ }^{26} \mathrm{Cfr}$. Giacomo Leopardi, Operette morali, 1982, Berkeley, University of California Press, trad. de Giovanni Cecchetti.

${ }^{27}$ Oscar Mandel, “Tragic reality”, en Laurence Michel y Richard B. Sewall (comps.), Tragedy: Modern essays in criticism, 1963, Englewood Cliffs, Prentice-Hall, pp. 60-61.

${ }^{28}$ Ibid., p. 101. 
Muchos pensadores más describen el trágico sentido de la vida: Michel de Montaigne, Blaise Pascal, Arthur Schopenhauer, Friedrich Nietzsche, León Chestov, Miguel de Unamuno, Albert Camus, Jean-Paul Sartre, Georges Bataille, Clément Rosset y Emil Cioran, entre otros. Aunque los términos son diferentes, el sentimiento es el mismo. Los filósofos trágicos son raros, pero la literatura retrata a menudo el sentido trágico de la vida: The heart of darkness de Conrad, Winterset de Maxwell Anderson, Absalom, Absalom de Faulkner, Long day's journey into night de O’Neil, Moby Dick de Melville, El extranjero de Camus, y La náusea y A puerta cerrada de Sartre, por nombrar solo algunos.

Los filósofos trágicos (por ejemplo, Nietzsche) ${ }^{29}$ nos inducen a aprender la lección y nos prometen alegría si lo hacemos. La alegría, a su vez, permite el conocimiento de la vida. Así como el amor solo es posible a través de la intimidad y la serenidad solo a través de la relajación, el conocimiento de la vida es necesario para alcanzar los más altos ideales éticos. Sin embargo, los filósofos trágicos no nos muestran un camino claro hacia la alegría. Nietzsche está particularmente confundido aquí, y su seguidor, Clément Rosset, describe más honestamente el estatus de gracia de Joy como similar a un regalo de Dios. ${ }^{30}$

Si encontráramos un camino hacia la alegría a través de la lucidez, tendríamos la garantía de una serenidad sostenida. En cambio, un uso sistemático del humor permite una exposición gradual a contradicciones más terribles cuya estructura incongruente observamos intelectualmente y toleramos emocionalmente gracias a la moderada tensión que el humor ofrece. Una visión objetiva, similar a aquella que busca la filosofía, ayuda a superar la tendencia a llamar trágico lo que nos pasa a nosotros, solo porque nos pasó a nosotros, mientras que nos parece cómico cuando le pasa a otro. En la misma línea, lo que será cómico en el futuro, cuando hayamos superado la situación, puede ser visto como cómico en medio de ella. Esto puede ser contrario a la psicología de la mayoría de las personas, pero también lo es la filosofía. Esto también

${ }^{29}$ Cfr. Nietzsche, The gay science, 1974, Nueva York, Random House, trad. de W. Kaufmann.

${ }^{30}$ Cfr. Clément Rosset, Joyful cruelty: Toward a philosophy of the real, 1993, Nueva York, Oxford University Press, trad. de David F. Bell. 
puede ser contrario a la risa espontánea, pero una disciplina del humor debe y puede ser enseñada al servicio de la realidad.

Si aceptamos que los seres humanos están condenados a un choque eterno entre los deseos y su satisfacción, la condición humana se presta a una doble y contradictoria caracterización como cómica y trágica. La posibilidad de caracterizar la condición humana como trágica y cómica es insuficiente para favorecer la interpretación cómica sobre la trágica. Se requiere un argumento adicional: algo que es a la vez trágico y cómico, o que tiene el potencial de ser trágico o cómico, no puede, en último término, ser únicamente trágico. Lo trágico carece de la capacidad de unir las contradicciones que posee lo cómico. Esto se denomina "inclusivismo cómico, en contraste con el exclusivismo de la visión trágica". ${ }^{31}$ Del mismo modo, John Crossan sostiene que "la tragedia es absorbida por la comedia", porque el hecho de que "el mismo mundo puede ser interpretado de estas maneras opuestas, es en sí mismo cómico". ${ }^{32}$ En Loopholes: Reading comically, John Burns ha intentado recientemente caracterizar la "comedia" como "fuera de las alternativas de lo trágico y lo cómico". ${ }^{33}$ Así, afirmo que una especie de visión cómica es la única visión que permite ver la condición humana simultáneamente como cómica y trágica. Si Walter Kerr tiene razón al decir que "no hay ningún acto en la vida que no sea, visto en su conjunto, a la vez trágico y cómico", ${ }^{34}$ la visión que se obtiene al incorporar los aspectos cómicos y trágicos de la vida es deseable porque es más rica y más fiel a los múltiples aspectos de la vida.

¿Cómo podemos caracterizar el nuevo nivel de conciencia cómica que incorpora tanto lo cómico como lo trágico en una visión estable? El humor que se produce al transponer las oposiciones trágicas en incongruencias cómicas es transitorio. Cuando se disuelve, el individuo se encuentra emocionalmente humillado y conceptualmente divertido por la conciencia de transmutar en forma repetida oposiciones trágicas en

${ }^{31}$ M. Conrad Hyers, The spirituality of comedy: Comic heroism in a tragic world, 1996, New Brunswick, Transaction Publishers, p. 40.

${ }^{32}$ John Dominic Crossan, Raid on the inarticulate: Comic eschatology in Jesus and Borges, 1976, Nueva York, Harper and Row, p. 21.

${ }^{33}$ John Bruns, Loopholes: Reading comically, 2014, New Brunswick, Transaction Publishers, p. xiv.

\footnotetext{
${ }^{34}$ Walter Kerr, Comedy and tragedy, 1967, Nueva York, Simon and Schuster, p. 28.
} 
incongruencias cómicas, con una capacidad siempre nueva de sufrir lo primero y sin resultados constantes de lo segundo.

Pero la repetición en sí misma es cómica, como señala Gilles Deleuze en Difference et repetition..$^{35}$ En Laughter: An essay on the meaning of the comic, Henri Bergson analiza la repetición como uno de los legados de lo cómico, ${ }^{36}$ y es muy conocido el dicho de Karl Marx de que la historia se repite primero como tragedia y luego como farsa. ${ }^{37}$ Sostengo que la conciencia que tiene lugar en vez del humor es el ridículo, la visión del ser humano como ridículo u Homo risibilis.

El Homo risibilis es una descripción adecuada de la humanidad debido a la necesaria seriedad y el consiguiente sufrimiento con el que nos tomamos a nosotros mismos y a nuestros esfuerzos, en conjunción con la opinión de que en la gran escala de cosas nosotros y nuestros esfuerzos son inútiles. A falta de pruebas de lo contrario, asumimos con razón este último punto de vista. Esto equivale a experimentar primero la realidad como trágica (la realidad es seria y causa sufrimiento) y a interpretarla luego como cómica (la realidad es inútil).

Otras teorías han intentado enseñarnos lecciones sobre humillación, frustración y la humildad que de ellas resulta. Su camino es más arduo, primero, porque implican presuposiciones metafísicas de cuyo conocimiento depende mi futuro bienestar, $\mathrm{y}$, segundo, los medios que proponen no están conectados con el fin que se persigue, lo que hace que sus lecciones sean intangibles y por lo tanto menos productivas. Sin embargo, una visión que utiliza el humor garantiza cierto placer en el proceso de aplicación: al estar necesariamente azucarada, la píldora se traga más fácilmente. Además, mirar la vida a través de sus incongruencias es más adecuado para los filósofos por su sensibilidad a las contradicciones tanto lógicas como éticas. Disfrutar las incongruencias obliga al filósofo a completar las limitaciones de la razón con el resto de su ser. Lo hace coherente como hombre e intelecto, como ser social y filósofo, como amante de la sabiduría y amante de la verdad.

${ }^{35}$ Cfr. Gilles Deleuze, Difference and repetition, 1994, Nueva York, Columbia University Press, trad. de Paul Patton.

${ }^{36} \mathrm{Cfr}$. Henri Bergson, Laughter: An essay on the meaning of the comic, 1999, Kobenhavn and Los Ángeles, Green Interger, trad. de C. Bereton y F. Rothwell.

${ }^{37}$ Cfr. Karl Marx, Der 18te Brumaire des Louis Napoleon, 1852, Moscú, Progress Publishers. 
Esta coherencia es posible porque se basa en la necesidad de estar en desacuerdo con uno mismo. Mientras que las teorías existencialistas de la autenticidad pueden afirmar lo mismo, carecen del atractivo para hacerlo realidad. En contradicción con el humor, la ansiedad, el aburrimiento, la náusea o el suicidio no son muy atractivos. En su intento de idear una ética a partir de la filosofía de Jean-Paul Sartre, Simone de Beauvoir señala la posibilidad de asumir el fracaso que es el ser humano: "El hombre se hace a sí mismo una carencia, pero puede negar la carencia como carencia y afirmarse como una existencia positiva. Entonces asume el fracaso... Para alcanzar su verdad, el hombre no debe intentar disipar la ambigüedad de su ser sino, por el contrario, aceptar la tarea de realizarla. Solo se reencuentra consigo mismo en la medida en que acepta mantenerse a distancia de sí mismo". ${ }^{38}$ No está claro, sin embargo, cómo se lleva a cabo tal cosa.

Es digno de mención que los teóricos del absurdo carecen de sentido del humor. Parecen olvidar que el absurdo es una categoría de lo cómico. Los dramaturgos del absurdo consideran que nuestro ridículo es trágico. Sin embargo, una visión cómica de la vida, fiel a sus aspectos trágicos y cómicos, está más allá de lo cómico y lo trágico. Una vez que se acepta el ridículo, desaparece. ${ }^{39} \mathrm{El}$ autoconocimiento y la autoaceptación nos liberan del ridículo. Recuperamos nuestra dignidad. Sin conflictos internos, somos libres de actuar en nombre de los demás.

Otros caminos que conducen a la alegría pueden lograr lo mismo. Sin embargo, hay una característica especial de la vida que se vive reconociendo plenamente el ridículo, ya que la dignidad personal y la autoestima no surgen de la comparación con los demás. Si Robert Solomon tiene razón al afirmar que "cada emoción es una estrategia subjetiva para la maximización de la dignidad personal y la autoestima", más preocupada por nuestra propia seguridad y estima que por la exactitud o la justicia, ${ }^{40}$ y Aaron Ben-Ze'ev tiene razón al asumir que cada emoción

${ }^{38}$ Simone de Beauvoir, The ethics of ambiguity, 1970, Nueva York, Citadel Press, trad. de Bernard Frechtman, p. 13.

${ }^{39} \mathrm{Cfr}$. Charles Baudelaire, De l'essence du rire, et généralement du comique dans les arts plastiques, en Oeuvres Complètes, 1968, París, Seuil.

${ }^{40}$ Robert C. Solomon, The passions: Emotions and the meaning of life, 1976, Nueva York, Doubleday, pp. 222-229. 
se basa en la comparación, ${ }^{41}$ entonces el hombre ridículo no encuentra utilidad alguna en la envidia, los celos, la ira y otras emociones comparativas. No hay nadie que sirva de comparación, ya que el ridículo iguala. Y la única autoestima de que disponemos proviene de nuestro sentido de la verdad, que, si se convierte en nuestra máxima suprema, es, al menos según Kant, "el máximo de la valía interior". ${ }^{42}$

Una visión igualitaria libre de los supuestos metafísicos requeridos por el cristianismo y el budismo es particularmente apta para fundar una ética de la compasión. La alegría no solo predice la ética, como indican Nietzsche, Spinoza y la investigación contemporánea, ${ }^{43}$ sino que también tiene una función epistemológica. Nos permite soportar más verdades sobre la realidad, lo que a su vez asegura el terreno de nuestra serenidad.

La serenidad o la tranquilidad es una meta de las filosofías y religiones orientales como el hinduismo, el budismo y el taoísmo, así como de las filosofías y religiones occidentales, como todas las filosofías helenísticas, el neoplatonismo y las filosofías de Spinoza y Santayana. Las religiones que apuntan a la redención también apuntan a la serenidad. Acabo de criticar estas filosofías y religiones por los medios que proponen para lograr este objetivo, pero creo que el objetivo es digno y está al alcance de la mano.

Entre estas filosofías destaca el pirronismo. Los pirronistas escépticos declararon gráficamente que la tranquilidad sigue a la suspensión del juicio como una sombra sigue al cuerpo: suspendemos todos los juicios debido a las dudas escépticas que socavan todas las afirmaciones dogmáticas del conocimiento, y la tranquilidad sigue a la suspensión del juicio - en términos técnicos, a la ataraxía sigue la epochēcomo una "sombra sigue al cuerpo". ${ }^{44}$ Esto significa que alcanzamos la tranquilidad como resultado de suspender el juicio sin intención de hacerlo. ${ }^{45}$

${ }^{41}$ Aaron Ben-Ze'ev, The subtlety of emotions, 2000, Cambridge, MIT Press, p. 18.

${ }^{42}$ Immanuel Kant, Anthropology from a pragmatic point of view, 2006, Cambridge, Cambridge University Press, trad. de R. B. Louden, p. 195.

${ }^{43}$ Michael Argyle, The psychology of happiness, 2001, Hove, East Sussex, Routledge, pp. 216-217.

${ }^{44}$ Diógenes, op . cit. 9.107.

${ }^{45}$ Sexto Empírico, Outline of scepticism, 1.25-30. 
Aparte de esta filosofía helenística y romana, la propuesta que aquí se esboza es la única visión escéptica del mundo que conozco que apunta a tal ideal y la única que utiliza el humor para alcanzarlo. Sin embargo, a diferencia de los pirronistas escépticos, cuya tarea es ardua, la que aquí se propone es más humilde. Además, es autocapacitante, debido al placer que el humor asegura y a la forma benévola en que uno se trata a sí mismo con humor. ${ }^{46}$ Además, el tipo de humor que se describe brevemente en este artículo y con detalle en otros lugares, puede aprenderse sin necesidad de habilidades cómicas especiales. Sus beneficios son proporcionales a su uso, y la serenidad que ofrece es gradual. El trágico sentido de la vida que asume es lo suficientemente común como para que sea útil para la mayoría o para todos los que deseen utilizarlo.

Finalmente, el Homo risibilis equivale a una congruencia armoniosa conmigo mismo, con los demás y con el mundo, una situación que todas las filosofías tratan de establecer en su intento de superar la alienación. Al considerar los conflictos como normales porque son constitutivos del complejo ser que soy y de las complicadas relaciones con y en un mundo que no comprendo plenamente, el Homo risibilis se hace eco de la frase de Heráclito: "No entienden que al estar en desacuerdo con uno mismo se cohesiona con uno mismo: una armonía que se estira hacia atrás, como de un arco o una lira". ${ }^{47}$ Cooper cita la conmovedora descripción de Wordsworth de la tensión latente en las emociones conflictivas que es el acicate del pensamiento filosófico:

El fundamento de toda filosofía verdadera es la diferencia entre [...] esa intuición $[\ldots]$ de nosotros mismos, como uno con el todo [...] y la de nosotros mismos como seres separados, que pone a la naturaleza en antítesis con nosotros. ${ }^{48}$

Muchas de las filosofías del mundo intentan resolver esta tensión ofreciendo relatos de seres humanos que hacen justicia a la singularidad

${ }^{46}$ Cfr. Sigmund Freud, "Humor", International Journal of Psychoanalysis, 9 (1928), pp. 1-6.

${ }^{47}$ H. Diels y W. Kranz, Die Fragmente der Vorsokratiker, B51, 80.

${ }^{48}$ David E. Cooper, World philosophies: An historical introduction, 1996, Oxford y Cambridge, Blackwell, p. 5. 
de la especie, pero sin convertir a sus miembros en monstruos, forasteros o extraños en el mundo. Lo que casi ningún filósofo de primer rango ha hecho es ignorar la tensión, porque "si el poeta alemán Hölderlin tenía razón y es a la vez 'divino y bueno' estar 'a la par' con el mundo, entonces el fracaso en la resolución de la tensión no es simplemente una debacle intelectual, sino una tragedia humana". 49

Si Cooper tiene razón sobre el impulso filosófico inicial, el punto de vista propuesto aquí se inserta en la historia de los intentos filosóficos para superar la alienación, y lo consigue, me parece, sin suposiciones injustificadas ni otras dificultades innecesarias.

Por medio de un proceso de múltiples etapas que involucra un uso sistemático del humor para disciplinar nuestro gusto por encontrar placer en incongruencias que no son inmediatamente divertidas para nosotros, se puede ascender por una escala de perfección que lleva a un estado que rivaliza con los más altos ideales filosóficos y religiosos. Este logro es gradual y se basa en el cambio de visiones según la capacidad de cada uno de transmutar el sufrimiento en alegría a través de la alquimia del humor. La lucidez que ganamos nos libera tanto de lo cómico como de lo trágico, al menos de esa parte de lo trágico que se ha transmutado en lo cómico y se ha convertido en constitutiva del protagonista tragicómico que nos describe a cada uno de nosotros. La libertad que resulta se caracteriza por la alegría, la felicidad y la paz.

${ }^{49}$ Loc. cit. 
Se prohíbe su reproducción total o parcial por cualquier medio, incluido electrónico, sin permiso previo y por escrito de los editores. 